\title{
Dalga Etkisindeki Şevli Yüzlü Dalgakıran Etrafında Oluşan Yerel Oyulmaların Farklı İrilikteki Taban Malzemesi Durumunda Sayısal Araştırılması
}

\section{Numerical Investigation of Wave Induced Local Scour Around Rubble Mound Breakwater for Different Grain Sizes of Bed Material}

\author{
Ali Temel 1, Mustafa Doğan 2*(C) \\ ${ }^{1}$ Dokuz Eylül Üniversitesi Fen Bilimleri Enstitüsü, Hidrolik-Hidroloji ve Su Kaynakları Programı, İzmir, TÜRKIYE \\ 2 Dokuz Eylül Üniversitesi Mühendislik Fakültesi, İnşaat Mühendisliği Bölümü, İzmir, TÜRKIYE \\ Sorumlu Yazar / Corresponding Author*: mustafa.dogan@deu.edu.tr \\ Geliş Tarihi / Received: 19.12 .2018 \\ DOI:10.21205/deufmd.2019216222 \\ Kabul Tarihi / Accepted: 21.02.2019 \\ Araștırma Makalesi/Research Article \\ Atıfșekli/How to cite: TEMEL, A., DOĞAN, M. (2019). Dalga Etkisindeki Şevli Yüzlü Dalgakıran Etrafinda Oluşan Yerel Oyulmaların Farkl \\ İilikteki Taban Malzemesi Durumunda Sayısal Araştırılması. DEUFMD, 21(62), 587-594.
}

Öz

Liman ve barınaklarda sakin su kesimleri olușturmak amacıyla inșa edilen dalgakıranlar etrafında yapının geometrisinden dolayı bozulan akım, yerel oyulmalara neden olabilmektedir. Oyulma ve yığılma şeklinde gözlenen deniz taban hareketleri, yapılarda stabilite kayıplarına ve hatta göçmelere yol açabileceğinden dolayı doğru bir şekilde belirlenmeleri son derece önemlidir. Dalgakıran topuğunda dalga kaynaklı oluşan yerel oyulmaların sayısal olarak incelendiği bu çalışma kapsamında Flow3D yazılımı yardımıyla 33 m uzunluğa, 3.6 m genișliğe ve $1.2 \mathrm{~m}$ derinliğe sahip bir sayısal dalga kanalı oluşturulmuştur. Gelişmiş hesaplamalı akışkanlar dinamiği (HAD) programlarından biri olan Flow3D kullanılarak düzenli dalga etkisinde dane medyan çapları $1 \mathrm{~mm}$, $0.55 \mathrm{~mm}$ ve $0.20 \mathrm{~mm}$ olan taban malzemeleri durumları incelenmiştir. Dalgakıran kesiti $3.6 \mathrm{~m}$ genişlik boyunca uygulamada sıklıkla kullanılan 2:3 şev eğimi oluşacak şekilde analiz edilmiştir. Çalıșma sonucunda elde edilen bulgular yorumlanarak, konu ile ilgili daha gelișmiş modeller için öngörüler oluşturulmuştur.

Anahtar Kelimeler: Şevli yüzlü dalgakıran, dalga etkisi, yerel oyulma, sayısal analiz, Flow3D

\begin{abstract}
Flow characteristics cause local scour due to configuration of rubble-mound breakwaters, constructed for various port structures which mainly require the formation of a still water zone. Hence, sediment transport observed as scour and deposition on the seabed has great importance for the stability of these structures. Within the scope of this study, a $33 \mathrm{~m}$ length, $3.6 \mathrm{~m}$ width and $1.2 \mathrm{~m}$ depth numerical wave model with Flow3D was used to observe wave-induced local erosion at the toe of rubble mound breakwaters. The condition of bed materials which have grain median diameter of $1 \mathrm{~mm}, 0.55 \mathrm{~mm}$ and $0.20 \mathrm{~mm}$ were examined using Flow3D, one of the advanced computational fluid dynamics (CFD) software. Geometry of breakwater was constituted and analyzed with slope 2:3 which is widely used in practice, along the $3.6 \mathrm{~m}$ channel width. The findings obtained were interpreted and predictions for more advanced models were formed.

Keywords: Rubble mound breakwater, wave-induced scour, local scour, numerical analysis, Flow3D
\end{abstract}




\section{Giriş}

Üç tarafı denizlerle çevrili ülkemizde özellikle son yıllarda kıyı yapılarının kullanımı ve bu yapılara olan talep her geçen gün artmaktadır. Kıyı koruma yapıları, kıyı yapıları arasında sıklıkla kendine yer bulanmaktadır. Bu yapıların arasında da dalgakıranlar, liman, marina, balıkçı barınağı vb. tesislerde konuşlandırıldıkları alanların gerisinde sakin bir su bölgesi oluşturmak amacıyla inşa edilmektedir. Bununla birlikte zorlu deniz koşullarında gerçekleşen dalgakıran inşaatı çok karmaşık ve maliyetli bir hal alabilmektedir. Bu nedenle kabul edilebilir güvenlik mertebelerine göre uygun maliyet, proje fizibilitesi açısından belirgin bir önem taşımaktadır.

Așınabilir bir deniz tabanı üzerinde yer alan dalgakıran eteğindeki oyulmalar, dalgakıran stabilitesini bozan ve önemle üzerinde durulması gereken bir husustur. Dalgakıranlar çoğunlukla aşınabilir deniz zemini üzerinde yer almakta ve dalga/akıntı gibi dinamik etkiler altında çevrelerinde yerel oyulmalar oluşmaktadır.

Tabanda meydana gelen oyulma, dalga karakteristiği, deniz taban malzemesi özellikleri yapının geometrisine bağlı olarak değişmektedir. Dalgakıranın bulunmadığı ortamda mevcut dalga şartlarında deniz tabanında önemli bir hareket yaşanmasa da dalgakıran inşaatı sonrası dalgakıran çevresinde sediment hareketi oluşacak ve bu durum stabiliteyi olumsuz etkileyecektir. Literatürde mevcut sınırlı sayıdaki çalıșmalarda dalgakıran kafa ve gövde bölgeleri ayrı ayrı ele alınmıștır. Bu çalıșmaların büyük çoğunluğu ise dalgakıran gövdesi civarındaki oyulmaların araştırıldığı çalışmalardır.

[1] çalışmasında, kırılmayan dalga koşulları altında düşey yüzlü dalgakıranlar için birtakım laboratuvar testleri yürütülerek bağıntılar elde edilmiştir. Askıda olmayan ve askıda kalan sediment için iki tip sediment tașınımı formülünü oluşturulmuștur. Askıda meydana gelecek sediment taşınımı için, $\mathrm{U}_{\mathrm{m}}$ tabanda oluşan maksimum su parçacığı yatay hızı, $U_{\text {cr }}$ sediment hareketi başlangıcındaki maksimum kritik su parçacığı hızı ve $\omega$ sediment çökelme hızı olmak üzere (1) eşitliği ile verilen ölçüt önerilmiştir.

$$
\frac{U_{m}-U_{c r}}{\omega} \leq 16.5
$$

$\mathrm{H}_{0}$ derin su dalga yüksekliği, h dalgalanmamış su derinliği ve Lo derin su dalga boyu olmak üzere göreceli maksimum oyulma derinliği ise (2) eşitliği ile verilmiştir.

$$
\frac{S_{\max }}{H_{0}}=\frac{C_{s}}{\left[\sinh \left(\frac{2 \pi h}{L_{0}}\right)\right]^{1.35}}
$$

[2] çalışmasında, düzenli dalga etkisinde düşey yüzlü dalgakıran kafasındaki oyulma derinliği (S) araştırılmıştır (Şekil 1). B dalgakıranın kafa genişliği ve $\mathrm{C}$ belirsizlik faktörü olmak üzere göreceli oyulma derinliği (3) eşitliği ile verilmiştir. Bu eşitlik, $\theta$ Shields parametresini göstermek üzere, yerel Shields parametresinin kritik Shields parametresinden ( $\left.\theta_{\text {cr }}\right)$ büyük olduğu hareketli taban oyulması koşulları için geçerlidir.

$$
\begin{aligned}
& \frac{\mathrm{S}}{B}=0.5 C\{1-\exp [-0.175(K C-1)]\} \\
& K C \geq r \quad \theta>\theta_{c r}
\end{aligned}
$$

Göreceli oyulma derinliğine etki eden ana etkenlerden biri Keulegan-Carpenter (KC) sayısının olduğu belirtilmektedir. Dalgakıran kafa genişliğine bağlı olarak, KeuleganCarpenter (KC) sayısı (4) eșitliğinde verildiği gibi tanımlanmıştır. $\mathrm{Bu}$ eşitlikte $\mathrm{U}_{\mathrm{m}}$ tabanda oluşan azami su parçacığı yatay hızı ve $\mathrm{T}_{\mathrm{w}}$ dalga periyodunu simgelemektedir.

$$
K C=\frac{U_{m} T_{w}}{B}
$$
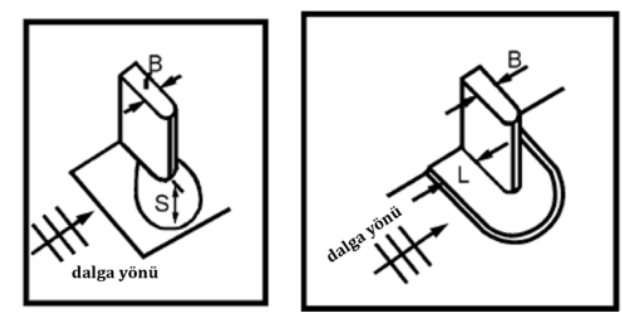

Şekil 1. Oyulma derinliğinin (S), dalgakıran kafa genişliği (B) șematik gösterimi

Taban kayma gerilmesini ilgilendiren değişkenler ile elde edilen boyutsuz Shields parametresi (5) eşitliği ile verilmektedir. $\mathrm{Bu}$ eşitlikte, $\mathrm{U}_{\mathrm{fm}}$ tabanda oluşan maksimum kayma 
hızını, s göreceli deniz taban malzemesi yoğunluğunu ve $\mathrm{d}_{50}$ deniz taban malzemesi dane medyan çapını simgelemektedir.

$$
\theta=\frac{U_{f m}^{2}}{g(\mathrm{~s}-1) d_{50}}
$$

[2] çalışmasında, dalga etkisi altında, düşey yüzlü dalgakıran kafası etrafındaki oyulmalar hem düzenli ve düzensiz dalga etkisi altında deneysel olarak incelenmiștir. Oyulma deneylerine bașlanmadan önce nispeten dar bir kanalda yalnızca akışla ilgili deneyler yapılmıș ardından geniş dalga kanalında hareketli taban koșulları ile deneyler gerçekleștirilmiștir. Deneylerde kullanılan taban malzemesi $\mathrm{d}_{50}=0.19 \mathrm{~mm}$ kalınlığında çok ince üniform kumdur. Deneyler sonucunda dalgakıran kafası civarında oluşan azami göreceli oyulma derinliği ile azami göreceli yığılma yüksekliği değerleri sırasıyla (6) ve (7) eşitlikleri ile ifade edilmiştir.
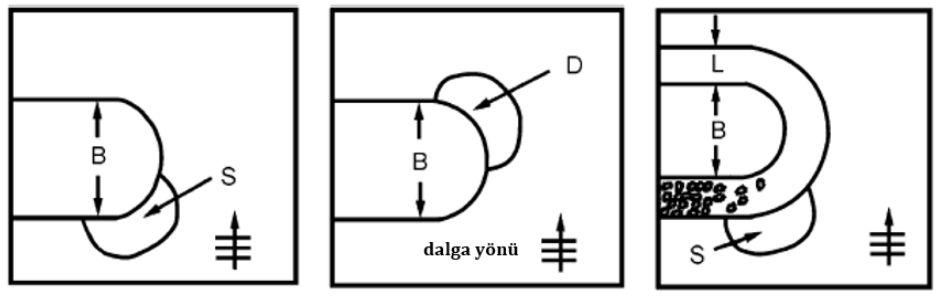

Şekil 2. Taş dolgulu dalgakıran kafa etrafındaki oyulma (S), yığılma (D) ve koruma tabakasının genişliği (L) şematik gösterimi

$$
\begin{aligned}
& \frac{S}{B}=0.04 C_{1}\left[1-e^{-4(K C-0.05)}\right] \\
& \frac{D}{B}=0.04 C_{1}\left[1-e^{-3.5(K C-0.05)}\right]
\end{aligned}
$$

[3] çalışmasında, şevli yüzlü taş dolgu dalgakıran için çalışmasında maksimum oyulma derinliğine $\left(\mathrm{S}_{\max }\right)$ etki eden dalga karakteristiklerini $\left(\mathrm{H}_{0}, \mathrm{~L}_{0}\right)$ ve su derinliği $(\mathrm{h})$ etkisini birleștirerek $\mathrm{S}_{\max } / \mathrm{H}_{0}$ ve $\mathrm{h} / \mathrm{L}_{0}$ oranlarını incelenmiştir. Ayrıca deniz tabanı sediment etkisini araştırmak Shields parametresini $(\theta)$ göz önünde bulundurmuşlardır. Şevli yüzlü dalgakıran gövdesi etrafındaki oyulma durumunda incelenen fiziksel olaydaki etkin büyüklükler $S / H_{w}=f\left(h / L_{w}, \alpha, \theta, L_{w} / d_{50}, R e, K C\right)$ şekilde verilmektedir.

Burada, $\mathrm{H}_{\mathrm{w}}$ dalga yüksekliğini, $\mathrm{L}_{\mathrm{w}}$ dalga boyunu, $\alpha$ şev açısını ve Re su parçacığı Reynolds sayısını göstermektedir. $\xi$ tabanda oluşan azami su parçacı̆̆ı yatay yer değiştirmesi, $v$ kinematik viskozite ve $\mathrm{Lr}$ tabanda oluşan kum dalgacıklarının uzunluğu olmak üzere Reynolds ve KC sayıları (8) ve (9) eșitlikleri ile tanımlanmaktadır.

$$
\begin{aligned}
& R e=\frac{\xi U_{m}}{\mathrm{~V}} \\
& K C=\frac{U_{m} T_{w}}{L_{r}}
\end{aligned}
$$

Dalgakıran etrafında oyulma olayında başlıca iki tip sediment taşınımı mevcuttur. Birincisi, askıda kalan sediment taşınımı ikincisi ise askıda olmadan sedimentin taşınması durumudur. Sediment taşınım tipi Shields parametresi $(\theta)$ ve sediment danelerinin çökelme hızının azami taban kayma hızına oranı $\left(\omega / \mathrm{U}_{\mathrm{fm}}\right)$ olan boyutsuz parametrelere bağlı olarak değișmektedir.

Dalga etkisi altında şevli yüzlü taş dolgu dalgakıran gövdesi etrafındaki oyulmalar hem düzenli hem düzensiz dalga etkisi altında deneysel olarak incelenmiștir. Çalışma $\mathrm{d}_{50}=0.2$ mm kalınlığındaki çok ince kum malzeme ile gerçekleștirilmiştir. Elde edilen göreceli oyulma derinliği bağıntısı (10) denklemi ile verilmektedir.

$$
\begin{aligned}
& \frac{S}{H_{w}}=\left[f(\alpha) /\left(\sinh \left(\frac{2 \pi h}{L_{w}}\right)\right]^{1.35}\right. \\
& f(\alpha)=0.3-1.77 \mathrm{e}^{\left(-\frac{\alpha}{15}\right)}
\end{aligned}
$$

Dalgakıran kafası etrafındaki oyulmaları incelerken bazı boyutsuz parametrelerin tanımı değişiklik göstermektedir. Şevli yüzlü dalgakıran kafası etrafindaki oyulma durumunda incelenen fiziksel olaydaki etkin büyüklükler $\mathrm{S} / \mathrm{B}=\mathrm{f}\left(\alpha, \theta, \xi / \mathrm{d}_{50}, \mathrm{Re}_{\mathrm{B}}, \mathrm{KC}\right)$ șeklindedir. 
Burada, $\mathrm{Re}_{\mathrm{B}}$ dalgakıran taban genișliğine göre hesaplanan Reynolds sayısını göstermektedir. Dalgakıran kafası etrafındaki oyulma durumunda Reв ve KC sayıları sırasıyla (11) ve (12) eșitlikleriyle tanımlanmaktadır.

$$
\begin{aligned}
& R e_{B}=\frac{B U_{m}}{\mathrm{~V}} \\
& K C=\frac{U_{m} T_{w}}{B}
\end{aligned}
$$

Çalışma sonunda, dalgakıran kafası etrafındaki oyulma sürecinde, kararlı akıș olușumu ve kafa bölgesinde dalgaların dalarak kırılması mekanizmalarının etkili olduğu anlaşılmıștır. Oluşan oyulma çukuru üzerinde esas olarak Keulegan-Carpenter sayısının etkin olduğu vurgulanmıştır.

[3] çalışmasındaki deney dalgakıranı, $0.6 \mathrm{~m}$ genişlik ve $0.8 \mathrm{~m}$ derinliğe sahip dalga kanalında, dalga üretecine $22 \mathrm{~m}$ uzaklıkta konumlandırılmıștır. Deneylerde düzenli ve düzensiz dalga etkisinde Şekil 3 'de görülen iki tip dalgakıran kesiti analiz edilmiştir.
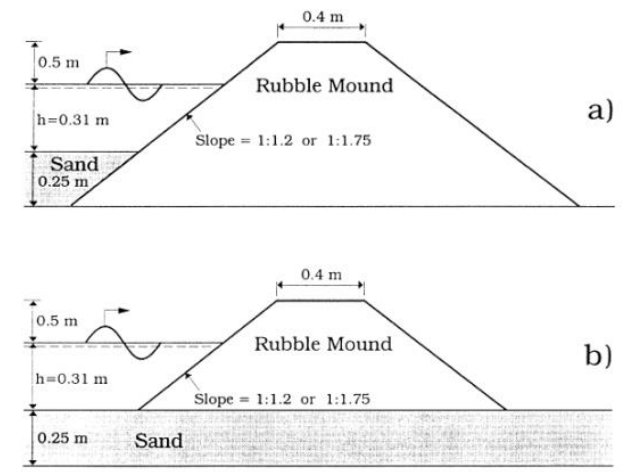

Şekil 3. [3] çalışmasında kullanılan dalgakıran enkesitleri

[1] çalışmasında (2) numaralı denklemde verilen $\mathrm{C}_{s}$ değerini askıda kalma durumunda olan ince kum için 0.3 , kaba daneli kum için 0.4 olarak vermiștir. [3] çalışmasında (10) numaralı denklemde $\mathrm{C}_{s}$ değeri yerine dalgakıran șev açısı $30^{\circ}$ ile $90^{\circ}$ arasında olmak koşuluyla şev eğimine bağlı $f(\alpha)$ fonksiyonunu tanımlamıştır. Deneysel çalıșmaların sonucu elde edilen (S/H-h/L) değerleri ve şekle ait lejant sırasıyla Şekil 4 ve Tablo 1' de verilmiștir.

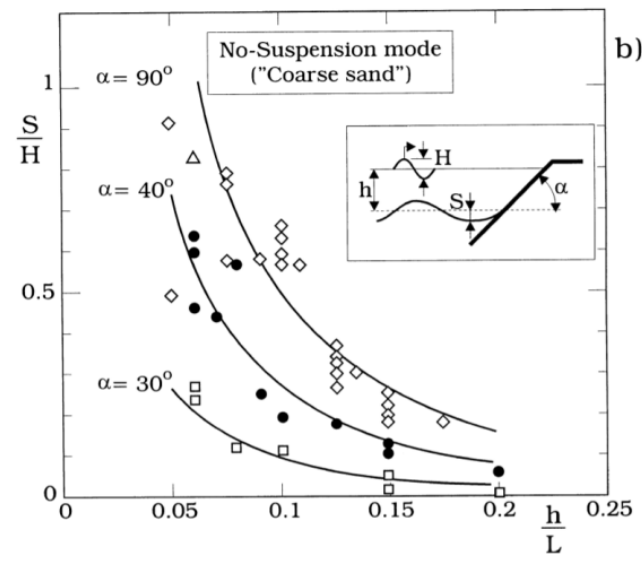

Şekil 4. Dalgakıranda maksimum oyulma [1] (Düz çizgiler (2) numaralı denklem sonucu için çizilen eğriler)

[4] çalışmasında, palyeli dalgakıranların stabilitesi üzerine deneyler gerçekleștirilmiștir. $\mathrm{Bu}$ çalışmada aşınabilir deniz tabanı durumu için oyulmalar ve dalga aşması durumu da incelenmiștir.

[5] çalıșmasında, düșey yüzlü dalgakıranlarında kafa etrafındaki oyulma derinliği ve koruyucu katman genişliği, oyulma ve birikme derinlikleri ile taş dolgu dalgakıranların kafa kesitlerindeki koruma katmanı genişliklerinin belirlenmesi için bir yaklaşım sunulmaktadır. Çalışma sonucundaki bulgular, Fredsoe ve Sumer (1997) sonuçları ile karşılaştırılarak yorumlanmıştır.

[6] çalışmasında, duran dalga etkisinde dalgakıran civarında akım ve oyulma yapısı dalgakıran dikliği değiștirilerek hem deneysel hem de sayısal olarak araştırılmıștır. Düşey yüzlü dalgakıran ve eğimli rijit dalgakıran ile gerçekleştirilen deneylerde kullanılan taban malzemesi, önceki çalışmalara benzer şekilde $\mathrm{d} 50=0.44 \mathrm{~mm}$ kalınlığında ince kumdur. Çalışma sonunda, geliştirilen sayısal modelin oyulma-birikme sürecinin modellenmesinde oldukça uygun olduğu deneysel veriler ile somutlaştırılmıştır.

[8] çalıșmasında, hafif eğimli kumlu bir deniz tabanında dik dalgalara maruz kalan batık dalgakıran tabanı boyunca iki boyutlu kıyıda yer alan oyulma karakteristikleri araștırılmıştır. Düzenli dalga kaynaklı oyulma özellikleri için kullanılan mevcut formüller, rastgele dalga kaynaklı oyulma özelliklerini türetmek için dalgaları bir sabit Gauss dar bant rastgele süreci olarak tanımlayarak birleştirmektedir. $\mathrm{Bu}$ 
özellikler; maksimum oyulma derinliği, oyulma çukuru genişliği, maksimum oyulma derinliği konumundan dalgakıran yüzüne olan uzaklığı hesaplama olanağı sunmaktadır.

[9] çalışmasında, hafif eğimli kumlu bir deniz tabanında dik dalgalara maruz kalan batık dalgakıran tabanı boyunca iki boyutlu kıyıda yer alan oyulma özelliklerinden türetilmiş bir olasılık yöntem sunulmaktadır.

[10] çalıșmasında, dalgakıran etrafındaki maksimum oyulmanın tahmini için genetik algoritma ve yapay sinir ağları kullanılarak bir model oluşturulmuştur. Bu model, göreceli su derinliği, Shields parametresi, kırılmayan dalga dikliği ve yansıma katsayısı kullanılarak oluşturulmuş; düzensiz dalga durumunda da $\mathrm{H}_{\text {rms }}$ ve $\mathrm{T}_{\text {pik }}$ ilave edilmiştir. Sonuç olarak geliștirilmiș modellerin, deneylerden türetilen ampirik formüllere göre çok daha iyi sonuç verdiğini göstermiştir.

Bu çalışma kapsamında farklı irilikte aşınabilir deniz zemini üzerinde yer alan șevli yüzlü dalgakıranlar etrafında düzenli dalga etkisi ile oluşan yerel zemin hareketleri sayısal olarak ele alınmaktadır. Sayısal analizler için Flow3D paket programı kullanılmıştır.

Tablo 1. Şekil 4 için verilen lejant

\begin{tabular}{llllll}
\hline Sembol & Şev Eğimi & $\mathrm{d}(\mathrm{cm})$ & $\mathrm{H}(\mathrm{cm})$ & $\mathrm{T}(\mathrm{s})$ & $\mathrm{d}_{50}(\mathrm{~mm})$ \\
\hline $\mathrm{C}$ & $1: 1.2\left(\alpha=40^{\circ}\right)$ & 31 & $6.3-12.7$ & $1.08-3$ & 0.2 \\
$\square$ & $1: 1.75\left(\alpha=30^{\circ}\right)$ & 31 & $6.3-12.7$ & $1.08-3$ & 0.2
\end{tabular}

\section{Sayısal Modelleme}

Gerçekleștirilen sayısal modellerde, dalga etkisi altında dalgakıran topuğundaki oyulma ve yığılmalar farklı irilikteki taban malzemesi durumunda araștırılmıștır. Modelleme çalıșması sonucunda deniz tabanı seviyelerindeki değișimler ve alansal oyulma desenleri belirlenmiștir.

Flow3D, çözüm için sonlu hacimler tekniğini kullanan ve bünyesinde bir çok türbülans modelini barındıran bir "Hesaplamalı Akışkanlar Dinamiği (Computational Fluid Dynamics)" paket programıdır. Flow3D aynı zamanda, problemin geometrisinin tanımlanmasını, çözüm ağı yapısının oluşturulmasını ç çözümün gerçekleștirilmesini aynı ara yüzde sağlayarak kullanım kolaylığı sunan bir yazılımdır. Flow3D paket programında incelenen probleme bağlı olarak bazı parametrelerin tanımlanması gerekmektedir.

Sayısal modelde, Dokuz Eylül Üniversitesi Hidrolik Laboratuvarındaki fiziksel dalga kanalına eș bir dalga kanalı modeli olușturulmuş olup dalga üretimi için fiziksel kanalda olduğu gibi plunger tipi bir dalga üreteci tanımlanmıştır. Dalgakıran ve topuğundaki kum bölgesine kadar olan bölümde $8 \mathrm{~cm}$, dalgakıran ve topuğundaki sediment için $4 \mathrm{~cm}$ aralıklı detaylı bir șekilde oluşturulan ağ sistemi Şekil 5 'te verilmektedir. 


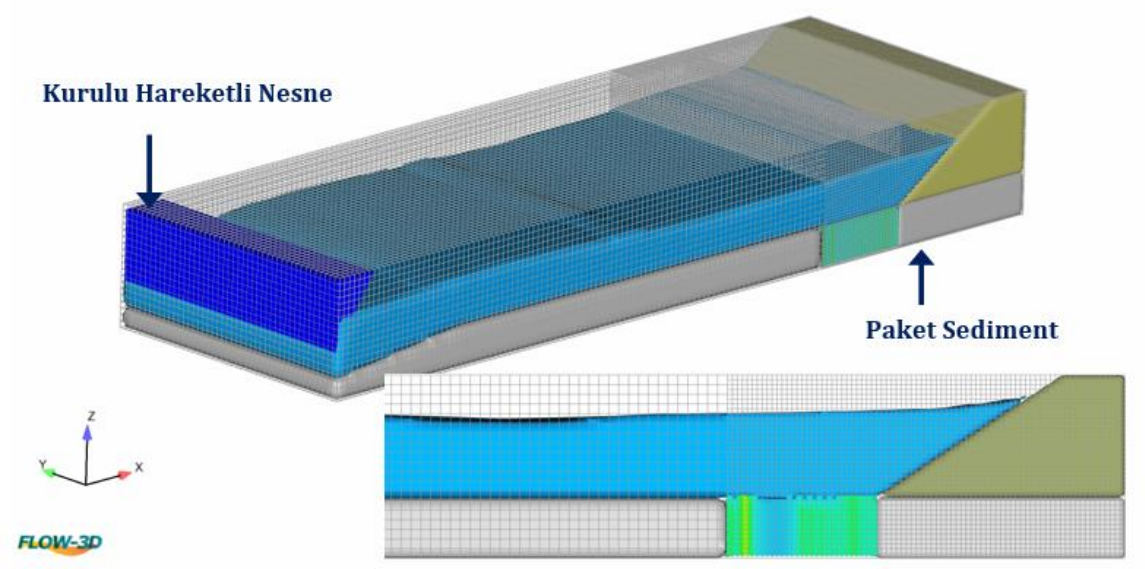

Şekil 5. Sayısal model ağ sistemi

Model dalgakıran her ne kadar şevli yüzeyli taş dolgu dalgakıran olarak düşünülse de, konu ile ilgili başlangıç araştırması niteliğindeki bu çalışmada taş dolgu dalgakıran yerine şevli düzlemsel yüzeye sahip geçirimsiz bir dalgakıran göz önüne alınmıştır.

Modelde aynı dalga koșullarında dalgakıran topuğunda 1 metre genişliğinde dane medyan çapı sırasıyla $1,0.55$ ve $0.20 \mathrm{~mm}$ olan paket sediment tanımlanmıştır. Belirli aralıklarla hareket eden cisim tanımlanıp, olușturulan dalga karakteristiği $\mathrm{H}=0.28 \mathrm{~m}$ ve $\mathrm{T}=1.7 \mathrm{~s}$, dalgalanmamış su derinliği ise $0.55 \mathrm{~m}$ olarak girilmiștir.
Flow3D yazılımında sayısal model kurulurken farklı türbülans modelleri seçilebilmektedir. Türbülans kapanış problemi için, ikinci yazarın birinde yürütücü ve birinde araștırmacı olarak yer aldığı ve dalga etkisi altında yapı-denizzemin etkileşiminin araştırıldığ $111 \mathrm{M} 550$ ve $215 \mathrm{M} 245$ projelerinde deneysel bulguların birbirleriyle uyumu incelendiğinde deneysel sonuçların sayısal sonuçlara en yakın türbülans modelinin RNG modeli olduğu Şekil 6'da görülmektedir.

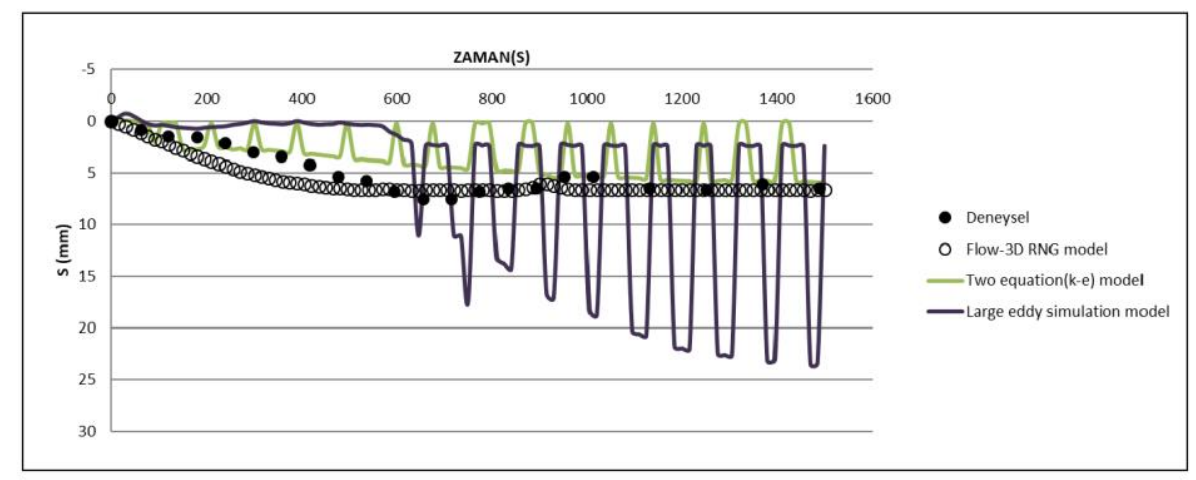

Şekil 6.Farklı türbülans modelleri ile elde edilen sonuçların deneysel sonuçlarla karşılaştırılması [4]

Akışkan özelliği olarak $20^{\circ} \mathrm{C}$ 'de su tanımlanıp, viskoz akış kabulü yapılan sayısal modellerde "Sediment scour" ve "Density evaluation" modelleri çalıștırılmıştır. Böylece öz kütle diğer parametrelerin bir fonksiyonu olarak hesaplanmaktadır. Kritik Shields parametresi
0.015, sürüklenme katsayısı (drag coefficient) kum için 1.5 olarak girilmiştir.

\section{Model Sonuçları ve Karşılaştırma}

Dalgakıran gövdesinin 2:3 şev eğimli, taban malzemesi $\mathrm{d}_{50}$ değeri $1,0.55$ ve $0.2 \mathrm{~mm}$ olan 
analiz için model çıtıları sırasıyla Sekil 7'den Şekil 9'a kadar verilmektedir. Sayısal model sonucu elde edilen çıktılarda oyulma desenleri açık bir șekilde görülmektedir. Dane çapı $1 \mathrm{~mm}$ olan analizlerde oyulma derinliğinin diğer analizlere göre düşük olduğu gözlenmiştir. Elde edilen bulgular doğrultusunda $0.55 \mathrm{~mm}$ dane çaplı taban malzemeli dalgakıran modelinde oyulmanın $1 \mathrm{~cm}$ mertebelerine yaklaștığ anlaşılmaktadır. Şekil 8 incelendiğinde sayısal model üzerinde seçilen iki noktada oyulma ve yığılmanın zamana bağlı değișimleri de görülmektedir. Özellikle oyulma (scour) için elde edilen zamana bağlı eğri, oyulma mekanizmasının beklenen genel gidiși ile son derece uyumludur. Son olarak $\mathrm{d}_{50}=0.20 \mathrm{~mm}$ taban malzemesi tanımlanarak sayısal analiz tekrar gerçekleștirilmiştir. Şekil 9'da verilen sonuçlar incelendiğinde oyulmanın maksimum $1.2 \mathrm{~cm}$ değerine ulaştığı görülmektedir. Şekil 7 ve Şekil 8'de verilen gösterime benzer şekilde, sayısal model üzerinde seçilen iki noktada oyulma ve yığılmanın zamana bağlı değişimleri de verilmektedir. (5) eșitliğinde verilen kritik Shields parametresi, üçüncü sayısal analizde $\mathrm{d}_{50}=0.20$ mm'ye bağlı olarak 0.025 olarak hesaplanarak programa girilmiștir.

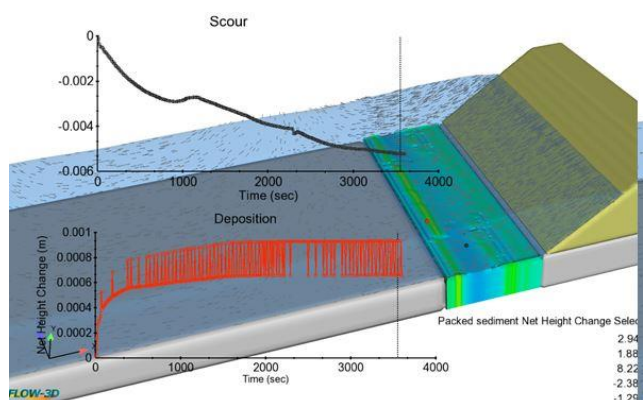

Elde edilen sayısal model sonuçlarının literatürde mevcut deneysel çalışma sonuçları ile karşılaştırılması istendiğinde, $\mathrm{d}_{50}=0.20 \mathrm{~mm}$ durumu için Sumer ve Fredsoe (2000) çalışmasına göre $S_{\max }=1.2 \quad \mathrm{~cm}$ olarak bulunmaktadır. Sayısal model ile elde edilen maksimum oyulma derinliği ile Sumer ve Fredsoe (2000) çalışmasına göre bulunan bu değer birebir örtüșmekte ve sayısal modelin güvenilirliğini ortaya koymaktadır. $\mathrm{d}_{50}=1$ ve $0.55 \mathrm{~mm}$ ile gerçekleştirilen sayısal model sonucunda ise beklendiği șekilde $\mathrm{d}_{50}=0.20 \mathrm{~mm}$ sonuçlarına göre daha düşük miktarda oyulma derinliği gözlenmektedir. Oyulma derinliğindeki bu azalma dane çapının büyümesi ile açıklanabilmektedir. Fiziksel olarak öngörüldüğü gibi benzer geometrik ve kinematik şartlarda dane çapı ile oyulma derinliğinin ters ilişkili olduğu belirlenmiștir.

$\mathrm{d}_{50}=0.20 \mathrm{~mm}$ sayısal model sonuçlarının Sumer ve Fredsoe (2000) çalışması sonuçları ile çok iyi uyum göstermesinin temel nedeni de Sumer ve Fredsoe (2000) çalışmasındaki deneylerde kullanılan temsili deniz taban malzemesi dane çapının $0.20 \mathrm{~mm}$ olmasıdır.

Şekil 7. 2:3 şev eğimli dalgakıran durumunda topukta oluşan oyulma deseni $\left(d_{50}=1 \mathrm{~mm}\right)$

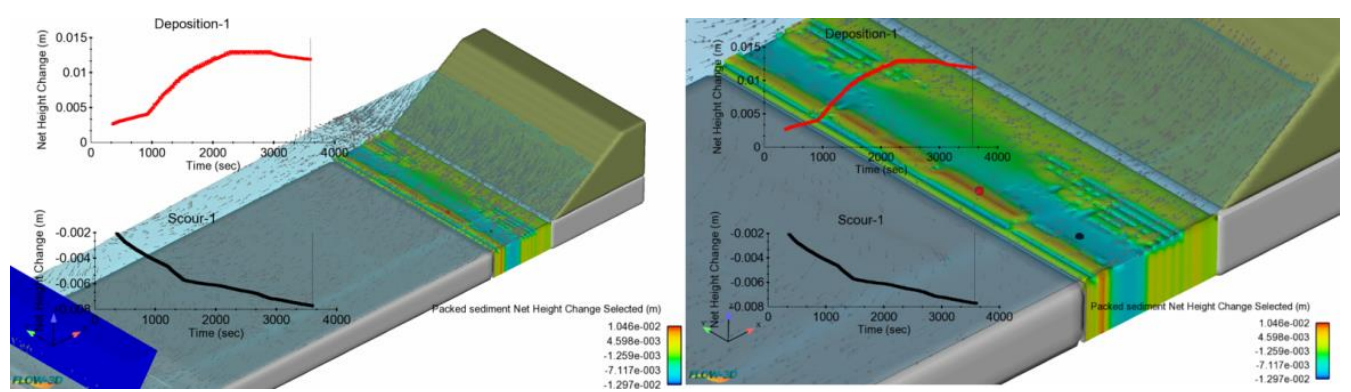

Şekil 8. 2:3 şev eğimli dalgakıran durumunda topukta oluşan oyulma deseni $\left(d_{50}=0.55 \mathrm{~mm}\right)$ 


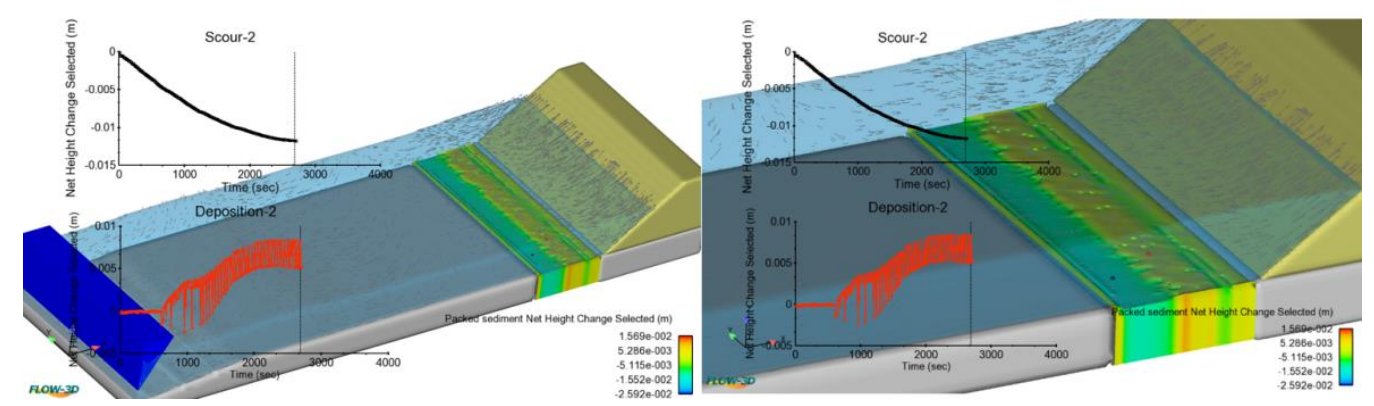

Şekil 9. 2:3 şev eğimli dalgakıran durumunda topukta oluşan oyulma deseni $\left(d_{50}=0.20 \mathrm{~mm}\right)$

\section{Sonuç ve Öneriler}

Sunulan çalışmada hesaplamalı akışkanlar dinamiği yazılımı olan Flow3D ile uygulamada sıklıkla kullanılan 2:3 şev eğimine sahip düzlemsel dalgakıran topuğundaki oyulmalar sayısal olarak araştırılmıştır. Elde edilen bulgular doğrultusunda dalgakıran modelinde oyulmanın, farklı irilikteki taban malzemesi ve kritik Shields parametreleri dikkate alındığında daha önce yapılmış olan deneysel çalışmalar sonucu çıkarılmış oyulma denklemleriyle oldukça uyumlu olduğu görülmüștür. Gerçekleștirilen çalıșma yukarıda sunulan sonuçlar yanında dalgakıran etrafında oyulma mekanizmasının sayısal olarak araştırılmaya devam edilmesine değer nitelikte olduğunu göstermektedir. Sayısal modelde yapılacak değişiklikler ile, geçirimli çekirdek durumu, beton bloklu koruma tabakası kullanımı, düşey yüzlü dalgakıran ve taş dolgulu kazıklı yapılar gibi kompleks deniz yapılarının farklı irilikteki deniz tabanı ile düzensiz dalga durumu gibi değişikliklerin oyulma mekanizması üzerindeki etkileri sayısal olarak araștırılmaya değer niteliktedir.

\section{Kaynakça}

[1] Xie (1981) "Scouring patterns in front of vertical breakwaters and their influences on the stability of the foundation of the breakwaters" PhD Thesis, TU Delft, Faculty of Civil Engineering and Geosciences, Hydraulic Engineering, 121 pages.

[2] B. M. Sumer, J. Fredsoe (1997) "Scour at the head of a vertical-wall breakwater" Coastal Engineering 29:201-230.

[3] B. M. Sumer, J. Fredsoe (2000) "Experimental study of 2D scour and its protection at a rubble-mound breakwater" Coastal Engineering 40:59-87

[4] A. Torum, F. Kuhnen, A. Menze (2003) "On berm breakwaters. Stability, scour, overtopping" Coastal Engineering 49:209-238

[5] Myrhaug, D., Rue, H., Torum, A. (2004) "Tentative engineering approach to scour around breakwaters in random waves" Coastal Engineering, 51, 10511065.
[6] Gislason, K., Fredsoe, J., Sumer, B.M. (2009) "Flow under standing waves Part 2. Scour and deposition in front of breakwaters" Coastal Engineering 56, 363-370.

[7] Myrhaug, D., Ong, M.C. (2009). "Random waveinduced scour at the trunk section of a breakwater" Coastal Engineering, 56, 688-692.

[8] Myrhaug, D., Ong, M.C. (2010) "Random waveinduced onshore scour characteristics around submerged breakwaters using a stochastic method" Ocean Engineering, 37, 1233-1238.

[9] Myrhaug, D., Ong, M.C. (2016) "Random waveinduced onshore scour characteristics around submerged breakwaters on mild slopes" Journal of Coastal Research, 75, 103-107.

[10] Pourzangbar, A., Losada M.A., Saber, A., Ahari, L.R., Larroude, P., Vaezi, M., Brocchini, M. (2017) "Prediction of non-breaking wave induced scour depth at the trunk section of breakwaters using Genetic Programming and Artificial Neural Networks" Coastal Engineering, 121, 107-118.

[11] M. Dogan (2018), "Kazıklı Kiyı Yapıları ile Kıyı Bölgesinde Yer Alan Rüzgâr Türbini Ayakları Etrafında Dalga Etkisi ile Oluşan Zemin Hareketlerinin Deneysel ve Sayısal Araștırması, Oyulmaya Karşı Koruyucu Önlemlerin Denenmesi" TÜBİTAK Proje Kodu: 3001 Proje No: 215M245. 